\title{
INTERHEART-Studie
}

\section{Das Herzinfarktrisiko liegt in der Familie}

\author{
Ein Herzinfarkt eines Elternteils erhöht \\ die Wahrscheinlichkeit für das gleiche \\ Ereignis bei den Nachkommen, unab- \\ hängig von bekannten biochemischen, \\ psychosozialen und genetischen \\ Risikofaktoren und dem Lebensstil.
}

In In der multinationalen INTERHEARTStudie wurden Daten von Probanden aus fünf ethnischen Gruppen aus aller Welt erfasst, darunter demografische, sozioökonomische, biologische (Begleiterkrankungen, Risikofaktoren), psychosoziale (z.B. Depression, Stress) und genetische Merkmale sowie die Lebensgewohnheiten (Ernährung, Nikotin- und Alkoholkonsum, körperliche Aktivität). Jetzt wurden 12149 Patienten mit einem ersten Herzinfarkt und 14467 Kontrollen miteinander verglichen. Wenn kein Herzinfarkt bei den Eltern aufgetreten war, wurde das Risiko gleich 1 gesetzt.

Das Infarktrisiko bei den Nachkommen erhöhte sich bis auf das 6,56-Fache in Abhängigkeit davon, ob ein oder beide Elternteile einen Herzinfarkt im Alter über oder unter 50 Jahren erlitten hatten. Wenn die genannten Einflussfaktoren für einen Herzinfarkt durch entsprechende statistische

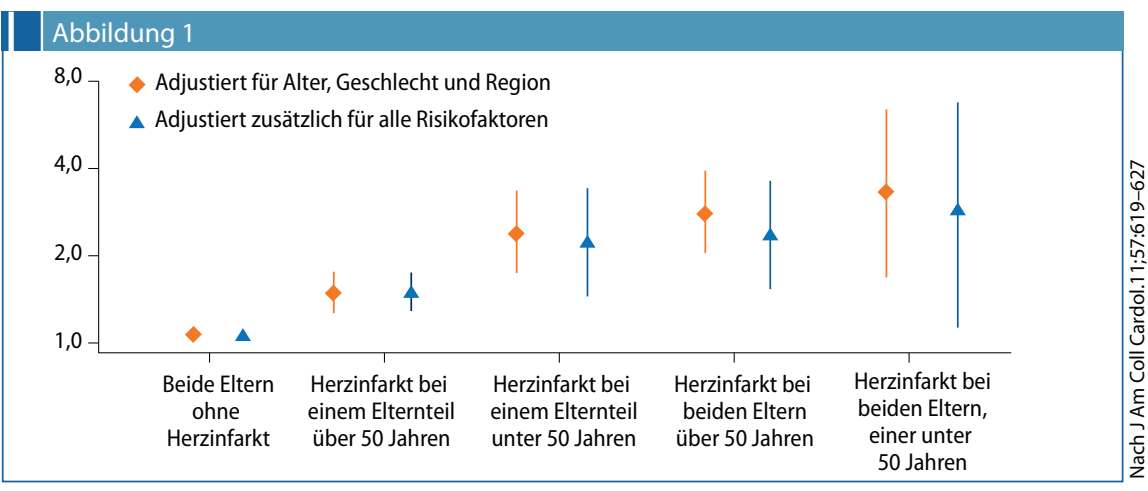

Beziehung zwischen Herzinfarkt bei Eltern und ihren Nachkommen.

Berechnungen berücksichtigt wurden, schwächte sich die Korrelation nur gering ab (Abb. 1).

II Kommentar: Die Tatsache, ob ein oder beide Eltern einen Herzinfarkt im höheren oder jüngeren Alter erlitten haben, bestimmt also eigenständig und unabhängig von allen bis heute bekannten Risikofaktoren die Wahrscheinlichkeit für einen Herzinfarkt bei den Nachkommen. Mit anderen Worten: Ein Herzinfarkt in der Familie erhöht das Infarktrisiko unabhängig vom Alter, von anderen Risikofaktoren und vom Wohnort.
Da die Berücksichtigung zahlreicher genetischer Merkmale den Zusammenhang nicht beeinflusst, sind die für das Infarktrisiko entscheidenden genetischen Varianten offensichtlich noch nicht identifiziert. Die Suche nach weiteren genetischen und nicht genetischen Risikofaktoren für einen Herzinfarkt wird weitergehen.

Prof. Dr. med. Heinrich Holzgreve, München II

II Chow CK et al. Parental history and myocardial infarction risk across the world. J Am Coll Cardiol. 2011;57:619-627

\section{Ideal für übergewichtige Diabetiker}

\section{Eiweißreiche Kost plus Krafttraining}

\section{Gewicht lässt sich am besten durch eine Kombination aus Ernährungs- umstellung und vermehrter Bewegung reduzieren. Welche Kombination ist bei Diabetikern am effektivsten?}

Übergewichtige und adipöse Frauen und Männer mit einem Typ-2-Diabetes und einem mittleren Body-Mass-Index von $35 \mathrm{~kg} /$ $\mathrm{m}^{2}$ wurden vier Gruppen zugeordnet: - Konventionelle Reduktionskost (KR; 19\% Eiweiß, 54\% Kohlenhydrate, 23\% Fett), - eiweißreiche Reduktionskost (ER; 33\% Eiweiß, 48\% Kohlenhydrate, 18\% Fett),
- KR + Kraftraining (KT; dreimal in der Woche über 45 Minuten) und

- $\mathrm{ER}+\mathrm{KT}$.

Der Energiegehalt der Reduktionskost betrug bei Frauen ca. $1400 \mathrm{kcal} / \mathrm{d}$ und bei Männern ca. $1700 \mathrm{kcal} / \mathrm{d}$. Er lag damit um ca. $1000 \mathrm{kcal} / \mathrm{d}$ unter dem täglichen Bedarf zur Gewichtserhaltung.

Die Gewichtsabnahme war nach 16 Wochen in beiden Diätgruppen ähnlich. Das Krafttraining steigerte die Gewichtsreduktion deutlich, vor allem bei einer eiweißreichen Kost (+53\%). Die proteinreiche Reduktionskost in Kombination mit einem
Krafttraining hatte die besten Auswirkungen auf die Körperfettmasse und den Bauchumfang. Eine geringe Abnahme der Muskelmasse (fettfreie Masse) konnte durch keine Therapieart verhindert werden.

Das kardiovaskuläre Risikoprofil besserte sich in allen Gruppen. Die Blutfette (Triglyzeride, LDL-Cholesterin, HDL-Cholesterin) normalisierten sich weitgehend, und die Parameter des Kohlenhydratstoffwechsels sowie der Blutdruck sanken erheblich (um 13-16/7-10 mmHg). Der $\mathrm{HbA}_{1 \mathrm{c}}$-Wert nahm in der Gruppe PR + KT um 1,8\% ab, in den anderen drei Gruppen um 1,1\%. Das Serum- 